\title{
Perspectivas de Segunda Pessoa na Era de Tecnologias de Informação
}

[Second Person Perspectives in the Information Technologies Era]

\author{
Mariana C. Broens»; Maria Eunice Q. Gonzalez $2^{\text {ॠ* }}$
}

Resumo: O objetivo central do presente artigo é analisar as relações de alteridade no contexto das tecnologias da informação e comunicação (TIC), partindo da perspectiva de segunda pessoa e ressaltando como as relações diretas de alteridade estão sendo significativamente alteradas pelo uso de TIC. Analisamos inicialmente teses centrais da perspectiva de segunda pessoa, problematizando críticas que tal perspectiva dirige à teoria da percepção direta. Introduzimos o conceito de affordances sociais e tecnológicas, visando clarificar o papel que elas desempenham nas relações de alteridade em sociedades informatizadas. Argumentamos que apesar de ganhos propiciados pelo uso de TIC na comunicação humana, uma de suas consequências indesejáveis nas interações sociais é confundir a experiência da alteridade na realidade ecológica com a da dita "realidade" virtual. Buscaremos apontar consequências pragmáticas da duplicação da experiência no contexto da "realidade" virtual, ressaltando seu possível impacto em hábitos sociais estruturadores das relações de alteridade.

Palavras-chave: Alteridade. Tecnologias da Informação e Comunicação. Percepção Direta. Realidade Virtual.

\begin{abstract}
Our central aim in this paper is to analyze alterity relations in the context of information and communication technologies (ICTs), from the second person perspective and highlighting ways in which the alterity of direct relations is being substantially changed by the use of ICTs. We firstly analyze central theses from the second person perspective, discussing some of the ways in which this perspective could affect the theory of direct perception. We then introduce the concept of social and technological affordances, aiming at clarifying their impacts on alterity relations in societies dominated by information technologies. We argue that despite the gains provided by ICTs in human communication, one of the undesirable consequences, in terms of social interactions, is confusion between alterity experienced in ecological reality and in the so-called virtual "reality". We shall try to point out pragmatic consequences of the replication of experience in the context of virtual "reality", highlighting its possible effects on social habits structuring alterity relations.
\end{abstract}

Keywords: Alterity. Information and Communications Technologies. Direct Perception. Virtual Reality.

\footnotetext{
${ }^{*}$ Professora Associada da Faculdade de Filosofia e Ciências da UNESP, Campus Marília. Bolsista de Produtividade em Pesquisa do CNPq - Nível 2. E-mail: mbroens@marilia.unesp.br. ORCID: https://orcid.org/0000-0003-1007-8576.

**Professora Associada da Faculdade de Filosofia e Ciências da UNESP, Campus Marília. Bolsista de Produtividade em Pesquisa do CNPq - Nível 1C. E-mail: eunice.gonzalez@unesp.br. ORCID: https://orcid.org/0000-0002-3837-4644.
} 


\section{Introdução}

Estudos sobre alteridade, envolvendo o outro com o qual podemos interagir, além de ter relevância para a Filosofia da Mente e da Psicologia, como ressaltaremos ao longo do texto, é de interesse para várias áreas do conhecimento, como a Filosofia da Informação e da Tecnologia, Antropologia e a História. Todorov (2019), por exemplo, apresenta uma tipologia da alteridade segundo a qual há pelo menos três eixos que envolvem as relações com o outro. O primeiro deles diz respeito aos valores éticos e econômicos que guiam a interação com o outro; o segundo referese a como as pessoas vão efetivamente interagir entre si na pragmática do cotidiano e, por fim, o terceiro eixo diz respeito à postura epistêmica a ser adotada em relação ao outro (p. 223).

Inspiradas por Todorov, em sua tentativa de compreender aspectos profundos das relações interculturais no período da colonização espanhola da América Central, adotaremos sua tipologia da alteridade para analisar o papel que o segundo eixo, o da pragmática do cotidiano em relação à conduta propriamente dita, pode desempenhar em nossas relações interpessoais. Argumentamos que, assim como diferenças entre as tecnologias da cultura espanhola e as das culturas pré-coloniais foram determinantes em suas interações, também inovações tecnológicas que atualmente permeiam as relações interpes- soais nas práticas de comunicação estão gerando significativas mudanças sociais. Ainda que seja difícil antecipar as consequências dessas mudanças sociais experimentadas nas sociedades informatizadas, sinais da influência de tecnologias de informação e comunicação (TIC) já começam a se fazer presentes nos processos constitutivos da identidade (inter) pessoal e coletiva.

O desenvolvimento de TIC vem alcançando patamares surpreendentes com o suporte de técnicas de Big Data, alterando as formas tradicionais da relação interpessoal, fonte fundamental de estruturação e manutenção de identidades de segunda pessoa. Originalmente ancorada na ação ambientalmente situada e historicamente incorporada, essa fonte está se deslocando para um espaço informacional líquido, estruturado muitas vezes por interesses midiáticos, econômicos e políticos. Nesse contexto, discutiremos o seguinte dilema contemporâneo sobre a natureza da relação comunicacional nos estudos de segunda pessoa: Partindo da hipótese de que a comunicação interpessoal humana expressa uma habilidade cognitiva enraizada em interações sociais, ambientalmente situadas e incorporadas, a transferência de parte dessa atividade para interações no espaço digital, mediado por máquinas, pode ser entendida: (a) como uma revolução (positiva e/ou negativa) na concepção de segunda pessoa, acompanhada de (b) uma perda/ganho de 
autonomia na qualidade de relações interpessoais supostamente privadas.

Admitindo que seres humanos e máquinas podem se comunicar com ganhos que, por vezes, facilitam a vida humana, qual seria o problema de se transferir o fardo mais tedioso e mecânico de nossas atividades comunicacionais para as máquinas? Dilemas contemporâneos que confrontamos na prática de nossas relações se manifestam, pois se, por um lado, a digitalização da informação abre inúmeras portas facilitadoras e atraentes de comunicação, por exemplo, entre pessoas geograficamente distantes, por outro lado esse mesmo recurso pode comprometer a qualidade das relações interpessoais, ameaçando o sentimento de confiança mútua, além de privacidade e autonomia.

Argumentamos neste artigo que, dentre as questões filosóficas contemporâneas relevantes, e urgentes, se incluem aquelas que refletem algum tipo de dilema pragmático e/ou ético envolvendo temas da confiança mútua, privacidade comunicacional, pessoalidade, identidade digital, polarização social e autonomia na era dos Big Data, entre outros. O estudo desses temas envolve dilemas que marcam e, em certa medida afligem, a nossa sociedade informatizada, cuja comunicação interpessoal tem sido até recentemente ambiental e historicamente situada.

Admitindo a hipótese de que a atividade de comunicação interpessoal ex- pressa uma habilidade humana constitutiva do conhecimento tácito de segunda pessoa, a seguinte questão direciona a presente investigação: Quais podem ser as possíveis consequências pragmáticas e éticas da transferência de parte da atividade de comunicação interpessoal para máquinas? Dentre as várias consequências, focalizaremos neste artigo a possibilidade de, em um futuro breve, ocorrer um comprometimento do sentimento de confiança mútua na qualidade de nossas relações interpessoais, acompanhado de mudanças significativas nas concepções vigentes de segunda pessoa.

$\mathrm{O}$ presente artigo está estruturado em três partes. Na primeira, apresentamos e comentamos a abordagem de segunda pessoa proposta por Perez e Gomila (2021), contrastando-a com uma concepção ecológica de relações interpessoais. Na segunda parte, introduzimos o conceito de affordance tecnológica indicando o seu papel na construção de relações interpessoais. Finalmente, na terceira parte, discutimos possíveis desdobramentos da evolução de affordances tecnológicas em ambientes digitais, incrementados por recursos de Big Data e suas implicações para a concepção contemporânea de interações de segunda pessoa. 


\section{Abordagens de segunda pessoa}

A abordagem de segunda pessoa de atribuição mental, segundo Perez e Gomila (2021), diz respeito a relações interpessoais que possuem um conjunto de traços comuns, dentre os quais destacaremos alguns. O primeiro deles é que interações de segunda pessoa seriam interações face-a-face envolvendo o reconhecimento de expressões (faciais e corporais) entre agentes, cujas ações propiciam a emergência de uma dinâmica fluente e contínua de interações mútuas. Perez e Gomila (2021) consideram, também, que as interações de segunda pessoa são "[...] mediadas por uma forma genuína de atribuição psicológica [...] uma forma de atribuição de um ponto de vista de segunda pessoa", a qual, segundo os autores, [...] envolveria a atribuição recíproca de estados mentais" (p. 29, tradução nossa).

Para explicar esta característica, de atribuição recíproca de estados mentais a outrem, os autores recorrem à célebre distinção entre processos puramente motores e estados intencionais frequentemente invocada por defensores da perspectiva de primeira pessoa. Por exemplo, a tentativa de recuperar o equilíbrio depois de uma pessoa ser empurrada por outra não caracterizaria, segundo Perez e Gomila (2021), interações de segunda pessoa por envolver uma relação de ajuste motor puramente reativa de um dos agentes envolvidos. Já a interação entre dois dançarinos ou membros de uma equipe esportiva demandaria a focalização da atenção dos agentes, isto é, de "[...] algum tipo de compreensão da informação socioperceptual disponível” (p. 29, tradução nossa). Entendem os autores que interações de segunda pessoa: "[...] envolvem um tipo especial de processo cognitivo que dá origem à atribuição de estados mentais entre os agentes em interação" (p. 29, tradução nossa).

Ao se referirem aos traços da atribuição mental na perspectiva de segunda pessoa, Perez e Gomilla (2021) buscam esclarecer que tal atribuição seria bastante diferente da atribuição de atitudes proposicionais presente no clássico debate entre as teses da Teoria-Teoria (que enfatiza o papel preditivo do vocabulário mentalista na atribuição de estados mentais) e a Teoria da Simulação (que ressalta a capacidade inata de simular estados mentais de outras pessoas sem a necessidade de uma mediação teórica). Ressaltam os autores que ambas as teorias estariam imersas no paradigma cognitivista internalista dos anos de 1980, segundo o qual capacidades cognitivas devem ser descritas como resultantes do processamento de representações simbólicas, sem considerar aspectos corporais e contextuais.

No entanto, parece que a abordagem de segunda pessoa proposta por Perez e Gomilla (2021) problematiza perspectivas internalistas, na atribuição de estados mentais aos outros, mas continua a privilegiar capacidades cognitivas de 
alto nível. Tal tipo de conhecimento diz respeito a capacidades consideradas de segunda ordem, as quais supõem habilidades teóricas, conceituais, proposicionais, mediadas por representações internas, como a capacidade de autorreferenciação. Mesmo reconhecendo o papel determinante do meio externo em relação aos conteúdos mentais, acabam assumindo teses sobre atribuição mental baseadas em habilidades teórico-proposicionais muito próximas às supostas por René Descartes (1979, p. 60-61). Em seus testes da linguagem e da ação, Descartes defende a tese antimecanicista da mente argumentando que máquinas e entidades não humanas não poderiam, em princípio, manipular adequadamente expressões linguísticas com significado e jamais agir racionalmente na realização de tarefas em múltiplos contextos.

Em suma, embora Perez e Gomila (2021) reconheçam a relevância cognitiva de fatores ambientais, corporais e ecológicos para a atribuição mental nas interações interpessoais, entendem que tais processos passam pela suposição de que conteúdos mentais, crenças e desejos, além de estados e capacidades a eles relacionados, estariam "na cabeça" e seriam elementos essenciais a tais relações. Nesse caso, qual seria, segundo seus postuladores, a novidade e a especificidade da abordagem proposta de segunda pessoa de atribuição mental?

Para contornar o conservadorismo representacionista da exigência de con- teúdos internos, Perez e Gomila (2021) defendem que as atribuições de segunda pessoa seriam "implícitas", uma vez que o agente não é consciente de efetuar tais atribuições (p. 30), e "diretas", no sentido de que "[...] na percepção significativa [...] no âmbito pessoal, a experiência é perceptiva, não de emergência de uma decisão ou raciocínio" (p. 30, tradução nossa). Desse modo, eles tentam conciliar a exigência prévia de mediação psicológica de segunda pessoa com a percepção direta de informação socialmente significativa, a qual não envolveria processos inferenciais conscientes.

Assim sendo, a perspectiva de segunda pessoa proposta por Perez e Gomila (2021) pretende conciliar pressupostos cognitivistas mais ou menos clássicos (pois haveria processos cognitivos de atribuição mútua de estados psicológicos desempenhando um papel mediador nas relações sujeito/sujeito/mundo) e os de uma teoria de percepção direta, segundo a qual expressões faciais e toda a gestualidade corporal seriam diretamente informativas para agentes envolvidos em experiências interpessoais.

Perez e Gomila (2021, p. 35) enfatizam que sua posição a respeito da percepção direta se distingue daquela defendida pela teoria da percepção/ação proposta por Gibson (2015) e demais estudiosos da percepção direta e da teoria ecológica da informação. Para Perez e Gomila (2021), o ponto de partida 
de Gibson em An ecological approach to visual perception é problematizar o argumento da "pobreza do estímulo", segundo o qual a informação percebida no ambiente deveria ser cognitivamente enriquecida, para propor, em seguida, uma teoria da percepção/ação que não necessitaria de processamento interno dos estímulos e segundo a qual, ressaltam os autores, não haveria a:

[... necessidade de postular processos perceptuais em um nível subpessoal - um argumento que não compartilhamos. No sentido que defendemos, então, percebemos diretamente muito mais do que objetos físicos e suas propriedades físicas. Podemos ver diretamente uma equação de segundo grau (se conhecemos análise matemática), vemos significados quando olhamos para um texto escrito, se sabemos ler; e podemos ver mesmo se vai chover ou se um objeto está a ponto de cair. Podemos também ver um Velázquez e, do mesmo modo, podemos ouvir a abertura de uma sinfonia ao invés de uma sequência de notas (PEREZ E GOMILA, 2021, p. 36, tradução e destaque nossos).

Pelas colocações acima, parece que Perez e Gomila (2021) consideram que a teoria gibsoniana da percepção se limitaria a tratar exclusivamente da percepção de entidades físicas e suas propriedades, não sendo suficiente para dar conta da percepção de obras ou produções culturais humanas. Entendemos que tal interpretação não leva adequadamente em conta dois conceitos centrais e concomitantes da teoria gibsoniana da percepção, quais sejam, o conceito de affordance e o de nicho.

Segundo Gibson (2015), a percepção de informação ecológica "[...] pela detecção de invariantes no fluxo de estímulos" (p. xiv, tradução nossa) é intrinsicamente significativa: affordances propiciam, diretamente, possibilidades de ação para os agentes que compartilham uma história ecológico-evolucionária com o meio em que vivem e no qual - ou pelo qual - se locomovem e interagem.

Além das affordances ecológicas propriamente ditas, Gibson ressalta que outros agentes no contexto ecológico oferecem informação sobre toda uma gama de possibilidade de interações sociais pela percepção direta de affordances sociais, especialmente relevantes para os estudos das relações de segunda pessoa. Aponta Gibson:

As diferentes substâncias do ambiente possuem diferentes affordances para nutrição e manufatura. Os distintos objetos do ambiente têm diferente affordances para manipulação. 
Acima de tudo, outros animais propiciam (afford) um rico e complexo cenário de interações - reprodutivas, de predação, de cuidado mútuo, de luta, de jogo, cooperativas e comunicativas. O que outras pessoas propiciam (afford) compreende todo o âmbito de significância social para os seres humanos. Prestamos especial atenção para a informação ótica e acústica que especifica o que a outra pessoa é, encoraja, ameaça e faz (p.135, tradução e destaques nossos)

Desse modo, affordances sociais incluem possibilidades de ação propiciadas diretamente por agentes em interação mútua e que dizem respeito a sua dinâmica de inter-relação motora, gestualidades e expressões faciais, intrinsecamente significativas. Mas, em contraste com a hipótese defendida por Perez e Gomila (2021), interações sociais na perspectiva ecológica não necessitam de uma atribuição mútua de estados psicológicos em segunda pessoa. Para a perspectiva ecológica, a percepção direta de possibilidades de interação entre agentes diz respeito à mutualidade dinâmica expressa em gestualidades corporais e expressões faciais significativas que envolvem affordances sociais indicadoras de cuidado, empatia, consolo e amizade ou de ameaça, humilhação, violência e hostilidade, por exemplo.

Como apontam McArthur e Baron (1983, p. 226), nas relações sociais, a percepção de expressões faciais e da dinâmica da gestualidade dos agentes, situados, em seus nichos, requer a detecção direta de informação social significativa e indicadora de possibilidades de interação, ao invés de uma experiência fenomenal de atribuição de estados psicológicos.

No que diz respeito ao conceito de $n i$ cho, por sua vez, Gibson ressalta que ele não pode ser confundido com ambiente ou mero habitat. Nicho, indica Gibson (2015), “[...] se refere mais a como um animal vive do que onde ele vive. Eu sugiro que um nicho é um conjunto de affordances" (p. 12, destaques do autor, tradução nossa).

Nichos humanos, como, por exemplo, nichos urbanos, também têm uma história de constituição progressiva, desde os primeiros grupos habitacionais até as cidades contemporâneas. Tais nichos urbanos, ao mesmo tempo em que foram alterando possibilidades de ação características de nichos rurais ou de pequenos assentamentos, são atualmente compostos pelos elementos tecno-culturais que propiciam a quem neles reside um vasto conjunto de possibilidades de ação e de affordances.

A partir das noções de affordance social e de nicho, propomos a seguinte caracterização ecológica de relação interpessoal: uma relação interpessoal pode se estabelecer por meio da percepção de 
affordances sociais, intrinsicamente significativas, que oferecem diretamente possibilidades de ação no fluxo da dinâmica informacional entre agentes em seus nichos. No plano individual, a percepção direta de affordances características de segunda pessoa requer convivência e familiaridade suficientes entre os membros de uma comunidade para evitar erros perceptuais dos mais variados tipos, frequentes em interações interculturais.

Uma vez inseridos em nichos urbanos contemporâneos, as tecnologias que neles se encontram integradas, como as TIC que envolvem recursos de computação ubíqua em rede, por exemplo, possibilitam novas experiências comunicativas e de relações interpessoais, propiciando, como indicaremos, uma revolução na concepção de segunda pessoa até recentemente experienciada em nichos ecológicos.

\section{Affordances tecnológicas e seus des- dobramentos nas relações interpesso- ais}

Para designar as possibilidades de interação social propiciadas pelas TIC, Quilici-Gonzalez et al. cunharam o conceito de tecno-affordance ressaltando suas propriedades disposicionais "[...] de segunda ordem emergentes de um sistema de percepção/ação" (2014). Kobayashi et al. esclarecem que "Tecno-affordances oferecem possibili- dades de ação no contexto do sistema ser humano-máquina. Elas são affordances humanas expandidas por meio de máquinas ou da internet das coisas" (2016, p. 87, tradução nossa).

Como indicamos, a percepção direta de possibilidades de interação não se limita a entidades físicas e suas propriedades, como alegam Perez e Gomila (2021). Em especial, interações sociais, inclusive as humanas, envolvem a percepção de possibilidades de ação oferecidas diretamente pela dinâmica corporal, sobretudo a facial, de outros agentes contextualmente situados. Ademais, atualmente, em muitos nichos urbanos, novas possibilidades de ação passaram a ser oferecidas por affordances tecnológicas. Assim, por exemplo, o uso do GPS e de outros dispositivos computacionais de localização ambiental permite aos usuários, familiarizados com esse tipo de aplicativo, captar informação sobre o local em que se encontram, bem como indicação sobre o seu direcionamento no ambiente em que circulam, atualizando as disposições adquiridas com o treino no uso desse dispositivo.

Affordances tecnológica, ou tecnoaffordances, seriam, então, propriedades disposicionais de segunda ordem porque, instanciadas em dispositivos computacionais de comunicação, viabilizam a percepção direta de possibilidades de ação e interações comunicacionais entre agentes humanos familiarizados com as TIC. Nesse con- 
texto, modifica-se a natureza das relações interpessoais situadas e incorporadas, uma vez que, embora comportem práticas de interação social que envolvem a percepção direta, sobretudo de aspectos visuais e sonoros, outros fatores relevantes presentes nas relações presenciais deixam de operar ou operam de outra forma quando são mediados por dispositivos de computação ubíqua.

As interações humanas nas sociedades contemporâneas estão permeadas por hábitos sociais que estabelecem padrões de conduta, como resultado de um "contrato social" emergente de processos auto-organizados, mesmo que este possa ser alvo de constantes adequações ou revisões. Conforme tais padrões, há hábitos coletivos de conduta social sedimentados e incorporados pelos agentes em seus nichos específicos. Assim, por exemplo, agressões gratuitas constituem uma exceção às normas de convívio social e não uma regra geral. Quando tais agressões ocorrem em interações presenciais, as pessoas agredidas poderão reagir em defesa de sua integridade, possibilidade essa que parece também operar como um fator de ajuste social limitador para prevenir e restringir abusos.

Em outros termos, relações interpessoais abusivas que ocorrem presencialmente foram socialmente enfrentadas e sofrem limitações, embora estas possam mudar conforme diferenças culturais e contextos sociais. A começar, em interações presenciais, a identidade do praticante de abusos, como gestualidades associadas a grupos supremacistas, por exemplo, tem pouca probabilidade de permanecer no anonimato, o que nem sempre ocorre em interações sociais computacionalmente mediadas.

Quando as interações sociais envolvem dispositivos de computação ubíqua, novas affordances tecnológicas socialmente relevantes, que ocorrem na fluidez do espaço virtual, ainda carecem de constraints reguladores emergentes de interações sociais coletivas. Assim, aspectos positivos e negativos das interações interpessoais, mediadas por dispositivos de computação ubíqua em rede, ganharam uma nova dimensão com o avanço de recurso de Big Data.

Ainda não existe um consenso sobre o termo Big Data, mas em sua acepção mais corriqueira ele designa recursos computacionais de coleta, mineração e organização de massiva quantidade de dados para fins de modelagens e previsão de eventos. Ampliando essa noção comum, Big Data será entendido aqui como um sistema de processamento de informação que envolve computadores extremamente potentes e algoritmos cuidadosamente projetados para coletar e analisar dados disponíveis através de recursos de computação ubíqua, que capturam continuamente variadas fontes de informação individual e coletiva. Nesse poderoso sistema de coleta e processamento de informação, a combinação e o reuso de dados por parte de téc- 
nicos e cientistas pode gerar não apenas novos dados, mas também descortinar e atualizar disposições na interação entre usuários de TIC, com consequências pragmáticas e éticas.

O uso apropriado de Big Data possibilita a elaboração de modelos explicativos e preditivos de eventos e situações em contextos bastante variados. Dentre os exemplos mais comuns, destacamse os modelos de previsão do tempo; identificação e controle de áreas contaminadas, ou de situações de risco ambiental em geral. Contudo, o seu emprego inapropriado também possibilita a propagação de desinformação, de fake news, deep fake além de reforçar disposições tendenciosas (preconceitos e estereótipos) de usuários de espaços digitais, gerando novas affordances tecnológicas que se multiplicam, resultando em dilemas nas perspectivas pragmática e ética.

Em resumo, dilemas pragmáticos e éticos surgem, então, em ambientes digitais, otimizados com recursos de Big Data, porque a informação disponível é extremamente dinâmica, gerando $a f-$ fordances tecnológicas que não envolvem, necessariamente, processos implícitos de atribuição de estados mentais. Por um lado, usuários familiarizados com interações em ambientes digitais, por exemplo em jogos que tradicionalmente eram jogados presencialmente, muitas vezes atualizam disposições e emoções extremadas na fluidez do ciberespaço. Por outro lado, essa mesma fluidez permite a exposição e também a quebra de padrões de comportamento preconceituoso, cristalizados em interações presenciais, nas quais operam diretamente constraints socioecológicos. Nesse contexto, urge investigar possíveis consequências pragmáticas e éticas da transferência de parte da atividade de comunicação interpessoal para máquinas que agora incorporam recursos de Big Data.

\section{A comunicação interpessoal na era dos Big Data}

- Em que sentido podemos atribuir pessoalidade a uma máquina que é diferente de nós? - Como assim?

Perguntou indignado um dos últimos humanistas do século 20 a um entusiasta internauta de ambientes virtuais que acabou de adquirir o seu mais recente avatar.

O que parece estar em jogo no diálogo acima não são apenas as clássicas disputas filosófica entre representacionistas e não-representacionistas, mecanicistas e antimecanicistas, mas diferentes perspetivas sobre o que se entende por pessoa e, mais ainda, sobre a alteridade no universo informacional contemporâneo. Situações e mundos possíveis, outrora inimagináveis, podem ser experienciados atualmente em 
ambientes virtuais constituídos de objetos virtuais.

Mas, qual seria a natureza dos objetos e ambientes virtuais? Uma resposta para essa questão é oferecida por David Chalmers no artigo The Virtual and the Digital. Nesse artigo, as seguintes características dos objetos digitais são enunciadas:

(1) objetos virtuais são objetos digitais reais,

(2) eventos em mundos virtuais são eventos digitais que realmente acontecem (envolvendo propriedades virtuais que são realmente instanciadas),

(3) experiências em realidade virtual envolvem percepções não ilusórias de um mundo digital,

(4) as experiências virtuais em um mundo digital podem ser tão valiosas quanto as experiências não virtuais em um mundo não digital. (Disputatio, vol. XI, No. 55, 2019, p. 454, tradução nossa)

A partir de (1)-(4), Chalmers explicita que objetos virtuais podem ser entendidos em pelo menos quatro sentidos:

- Em um primeiro sentido, restrito, um objeto digital é um bit: um 0 ou 1 em um sistema computacional.
- Em um segundo sentido, um objeto digital é uma estrutura de dados: um objeto computacional constituído por bits, mas é também individualizado computacionalmente.

- Em um terceiro sentido, um objeto digital inclui qualquer objeto totalmente baseado em estruturas de dados (e talvez outros objetos baseados em bits), seja ele (ou não) uma estrutura de dados, ou individualizado computacionalmente. Em um quarto sentido, um objeto digital inclui qualquer objeto baseado em estruturas de dados (e / ou bits) e propriedades mentais (Chalmers, 2019, p. 456, tradução adaptada).

Em resumo, segundo Chalmers, objetos virtuais são objetos reais que podem ser caracterizados em vários sentidos, todos eles constitutivos de eventos digitais, igualmente reais. A tese polêmica de Chalmers que nos interessa aqui é aquela segundo a qual os objetos e eventos virtuais possibilitam a percepção (não ilusória) constitutiva de experiências virtuais que podem ser tão valiosas quanto experiências no mundo não digital.

Chalmers (2019) ressalta que os usuários precisam estar familiarizados com ferramentas no ambiente virtual para que as experiências no mundo digital possam ser tão valiosas quanto aquelas do mundo não virtual. Essa condição permite classificar os usuários em experts, aprendizes e iletrados digi- 
tais, com implicações para a percepção da identidade e do reconhecimento de relações sociais interpessoais. Idosos, por exemplo, em situações de fragilidade, podem se enquadrar na categoria de iletrados digitais, enquanto jovens e crianças que têm acesso às mídias tendem a se enquadrar nas outras duas categorias.

A expressão analfabeto digital já começa a se instalar no linguajar comum para identificar aqueles (outros) que, em contraste com os experts familiarizados com as rápidas inovações tecnológicas, preservam seus hábitos convencionais em suas formas de comunicação interpessoal. Nesse sentido, a adoção do realismo virtual no contexto de práticas de comunicação individual e coletiva pode gerar, em um futuro não muito distante, significativas mudanças em nossas relações interpessoais. Sem entrar em detalhes sobre as vantagens e desvantagens de se abraçar o realismo virtual e as características dos objetos digitais, como sugerido por Chalmers (2019), entendemos que experiências no universo virtual não podem ser propriamente equiparadas àquelas experiências no mundo não virtual, por pelo menos três razões:

(i) Experiências no mundo não virtual envolvem habilidades desenvolvidas através de práticas corporais, ambientalmente situadas e compartilhadas coletivamente, ao longo do processo histórico de interações constitutivas da vida social cotidiana, que carac- terizam um tipo de conhecimento tácito (que Gilbert Ryle denomina Know-how (2009, p. 17 e seguintes)). Uma propriedade desse tipo de conhecimento é que mesmo sem o emprego de palavras, o conhecimento tácito pode indicar affordances sociais valiosas que envolvem relações de confiança em vários planos da existência.

(ii) O conhecimento tácito, próprio do Know-how, parece estar sendo rapidamente alterado nas relações interpessoais em ambientes virtuais, incrementados com recursos de técnicas de análise de Big Data, nos quais relações de confiança se mostram fluídas.

(iii) Jovens e crianças usuários de redes sociais estão desenvolvendo habilidades tecnológicas importantes, mas frequentemente o fazem em detrimento daquelas habilidades que envolvem destreza motora, participação na vida cultural de seus nichos e aquelas que costumeiramente demandam interações situadas e incorporadas. Alguns resultados da ausência de interações físicas e sociais, com a prevalência de relações no universo virtual, já se fazem sentir individual e coletivamente.

As razões (i)-(iii) indicam dificuldades que precisam ser enfrentadas em nossa comunicação no universo virtual, concernentes aos dilemas pragmáticos e/ou éticos sobre o problema de se transferir o fardo tedioso de nossas atividades comunicacionais para as máquinas. É difícil ignorar aspectos positivos da virtualidade, em especial na 
disponibilidade da comunicação à distância em tempos de pandemia, em que a fragilidade humana, diante da dor e do medo da morte, fica evidente. Contudo, cabe atentar para as rápidas mudanças concernentes às concepções habituais de segunda pessoa, confiança mútua, privacidade, autonomia e identidade pessoal e coletiva, concepções essas construídas na comunicação interpessoal historicamente situada e incorporada em ambientes ecológicos nãovirtuais.

Apesar de inúmeros conflitos, competições e guerras que marcam a história humana em ambientes ecológicos, a confiança mútua tem desempenhado um papel fundamental nas relações de segunda pessoa. Entendemos que a confiança mútua constitui elemento indispensável para o estabelecimento e a preservação de relações interpessoais, desde aquelas que envolvem atos de fala, para cuja efetivação há uma série de acordos tácitos sobre o significado e os modos de compartilhá-los, até as relações do dia a dia diretamente relacionadas à sobrevivência.

Conforme apontam Kobayashi et al. (2015), a confiança mútua pode ser caracterizada como uma propriedade disposicional auto-organizada e reforçada por processos de feedback que envolvem affordances sociais indicadores de conduta benevolente ou não malevolente. Em relações que demandam confiança mútua, hábitos de conduta benevolentes ou não malevolentes são elementos fundamentais, na medida em que revelam tendências recorrentes de agir de um modo dado em circunstâncias semelhantes.

Relações de confiança, inclusive, compõem a história humana desde suas origens mais remotas. Conforme indicam estudos de Psicologia Social, a expectativa de cuidado mútuo e de condutas cooperativas focadas no bem comum, inicialmente no núcleo familiar e posteriormente ampliada para a comunidade, parece ter desempenhado papel central na constituição da tecitura sociocultural das organizações humanas.

Em nossa realidade social compartilhada até o presente, a confiança mútua desempenha papel estruturador de certos hábitos e disposições que perduram até nossos dias (Trivers, 1971; Baumeister e Vohs, 2007; Van Lange, Higgins e Kruglanski, 2020). O papel social estruturante das relações interpessoais de confiança mútua decorre, na perspectiva da filosofia ecológica, de interações que se estabeleceram a partir de affordances sociais de gestualidades de encorajamento, quando se trata de condutas benevolentes, ou de repreensão, estes últimos envolvendo restrições e admoestações de desencorajamento diante de ações perigosas ou nocivas a membros do grupo.

Em suma, a percepção direta, não mediada, de encorajamento ou de repreensão de condutas na realidade social compartilhada que envolve confiança mútua tem sido um dos elementos 
estruturantes das relações sociais humanas constitutivas da segunda pessoa. Em diferentes nichos ecológicos, o outro se apresenta como um ser pertencente ao universo regido por affordances sociais indicadores de sua conduta e de conhecimento tácito.

As relações sociais humanas constitutivas da segunda pessoa vêm se alterando em ambientes virtuais com a utilização, por exemplo, de disguisers (algoritmos que possibilitam a criação e a alteração de partes ou da totalidade de imagens da identidade de usuários de redes sociais) facilitando a criação de parceiros virtuais com identidades alteradas. Exemplos de disguisers incluem adultos que se disfarçam online de crianças ou adolescentes para se fazerem presentes nas mais diversas situações. Agentes de segurança, pública e privada, também tiveram suas atividades de controle e monitoramento facilitadas nesse ambiente.

Um outro exemplo de alteração radical das relações sociais em ambientes virtuais é o de sistemas de recomendação (RS - do inglês recommendation systems), guiados efetivamente por robôs, que se espalham em ambientes digitais norteados por interesses econômicos, visando influenciar a opinião de usuários no que diz respeito às possibilidades de compra de bens e serviços. Destaque tem sido dado aos bens de consumo de moda que moldam a aparência dos usuários segundo padrões estabelecidos pelo mercado.
Um detalhe relevante sobre os sistemas de recomendação é que, na tentativa de construir relações de confiança comercial que pretendem simular interações entre pessoas, eles empregam informação obtida dos usuários, muitas vezes sem seu conhecimento e/ou consentimento, para influenciar o processo de venda de produtos ou serviços. Esse emprego de informação disponibilizada pelo usuário traz à tona problemas pragmáticos e éticos sobre privacidade informacional. Tais problemas surgem porque, embora a noção de privacidade possa ter diferentes abrangência e significado por conta de especificidades culturais ou geracionais, há um certo consenso sobre a relevância de preservação de aspectos da intimidade que se deseje omitir em relações interpessoais.

No cenário acima esboçado, cabe questionar: o que poderá ocorrer nas relações de confiança mútua quando as interações sociais se dissolvem na realidade virtual e em interesses comerciais velados, limitando as possibilidades de encorajamento ou de repreensão de condutas? Na ausência ou ineficácia de normas reguladoras da conduta moral, várias maneiras de desinformação se propagam no meio virtual volátil, em que pessoas aparecem e desaparecem no clicar de uma tecla de computador, independente dos eventuais desrespeitos à intimidade e das quebras de confiança que possam ter provocado.

Entendemos que contribuições rele- 
vantes podem ser oferecidas pela filosofia através de uma nova agenda de temas e questões que permitam avaliar possíveis consequências pragmáticas e éticas (positivas e negativas), no estudo das relações de segunda pessoa decorrentes da acolhida do realismo virtual, como aquele proposto por Chalmers (2019). Para concluir, sugerimos temas e questões que poderiam ser incluídas nessa nova agenda.

\section{Considerações Finais}

Iniciamos este artigo apresentando os três eixos, segundo Todorov (2019), que envolvem as complexas relações de alteridade: (1) o eixo dos valores, (2) o eixo da conduta e (3) o da postura epistêmica a ser adotada em relação ao outro. Assumindo essa tipologia, nos limitamos a analisar questões pertencentes ao eixo (2), da pragmática do cotidiano das relações interpessoais, focalizando dilemas pragmáticos e éticos concernentes às relações interpessoais em ambientes digitais.

Apresentamos a abordagem de segunda pessoa proposta por Perez e Gomila (2021) para, então contrastá-la com uma concepção ecológica de relações sociais interpessoais, ressaltando o papel das affordances sociais e tecnológicas na construção e identificação de relações interpessoais através do uso de TIC. Destacamos a evolução de affordances tecnológicas em ambientes digi- tais através de recursos de Big Data, indicando possíveis implicações pragmáticas e éticas de seu desenvolvimento acelerado no conhecimento tácito subjacente à confiança mútua nas relações interpessoais.

Sem a intenção de propor soluções para os dilemas indicados, mas entendendo que a filosofia possui um papel relevante na compreensão de possíveis implicações pragmáticas e éticas decorrentes do desenvolvimento de TIC em ambientes digitais, propomos a seguinte agenda de temas e problemas concernentes à percepção de segunda pessoa:

a) O desenvolvimento de TIC e sua influência em atividades práticas, que envolvem o "saber como" atuar em meios digitais, deve ser cuidadosamente investigado visando o bem comum.

b) $\mathrm{O}$ realismo virtual proposto inicialmente por Chalmers (2019) merece uma discussão filosófica ampla, com vistas ao entendimento de métodos e técnicas de estruturação da informação digital em meios virtuais, em especial nos estudos de segunda pessoa.

c) A ética do cuidado mútuo e a possibilidade de responsabilização dos usuários de TIC deveriam ser priorizadas para prevenir abusos e a proliferação de hábitos malevolentes nas relações interpessoais, virtuais e não virtuais.

d) Formas de conhecimento precisam ser compartilhadas sobre os modos de operação de estratégias desinformativas, em especial nas redes sociais, pode 
contribuindo para minimizar o alcance e a eficácia de processos informacionais que buscam, deliberadamente, manipular informação afetando, entre outros, as formas de interação interpessoal e os graus de autonomia da ação coletiva.

Entendemos que a agenda esboçada de temas e problemas a serem enfrentados deveria ser priorizada no debate contemporâneo em Filosofia da Tecnologia e da Informação em seu diálogo interdisciplinar com outras áreas das Ciências Sociais aplicadas, especialmente no que tange ao debate sobre políticas públicas cujo objetivo seja pre- servar a dignidade da pessoa em suas interações, tanto as efetivas quanto as virtuais.

O estabelecimento de relações de confiança mútua no mundo virtual exigirá um esforço coletivo, transnacional, de regulação no ecossistema virtual semelhante ao que existe no ecossistema social não virtual. Esse esforço pode ser facilitado por reflexões filosóficas voltadas às questões pertinentes ao domínio da vida cotidiana que valorizam a pragmática do conhecimento tácito que parece estar em risco nas interações interpessoais da sociedade contemporânea.

\begin{abstract}
Agradecimentos: Somos gratas a José Artur Quilici-Gonzalez, por sua sugestão sobre dilemas pragmáticos e éticos no contexto de tecnologias digitais e também pela cuidadosa leitura crítica; aos membros do Grupo Acadêmico de Estudos Cognitivos da UNESP e do grupo Auto-Organização do CLE - UNICAMP pelas ricas interações teóricas que oferecem, e à UNESP, à FAPESP e ao CNPq pelo apoio institucional.
\end{abstract}

\title{
Referências
}

BAUMEISTER, R. F. VOHS, K. D. (Eds) Encyclopedia of social psychology. Thousand Oaks, London, New Delhy and Singapore: Sage Publications, 2007.

CHALMERS, D. The virtual as the digital. Disputatio, 11 (55):453-486, 2019.

GIBSON, J. J. The ecological approach of visual perception. Classic edition. New York: Psychology Press, 2015.

KOBAYASHI, G.; BROENS, M. C.; GONZALEZ, M. E. Q.; QUILICI-GONZALEZ, J. A. The Internet of Things and its Impact on Social Relationships Involving Mutual Trust In: IEEE International Symposium on Technology in Society (ISTAS), 2015, Dublin. IEEE International Symposium on Technology in Society (ISTAS) Proceedings. Dublin: IEEE, 2015. v.1. p. 6.

LANGE, Paul A. M. van; HIGGINS, E. T KRUGLANSKI, A. W. (Eds.) Social psychology: handbook of basic principles. Third edition. New York: The Guilford Press, 2021.

MCARTHUR, L. Z;; BARON, R. M. Toward an Ecological Theory of Social Perception. Psychological Review 90 (3): 215-238. 1983.

PEREZ, D. GOMILA, A. The second person: Social cognition in human interaction. London and New York: Routledge, 2021. 
QUILICI-GONZALEZ, J. A.; BROENS, M. C.; GONZALEZ, M. E. Q; KOBAYASHI, G. Complexity and information technologies: an ethical inquiry into human autonomous action. In: Scientiae Studia (USP), v. 12, p. 161-179, 2014.

RYLE, G. The concept of mind. Introduction Julia Tanney. London and New York: Routledge, 2009.

TODOROV, T. A. Conquista da América. Trad. Leila Perrone Moises. 5a. Ed. São Paulo: Martins Fontes: 2019.

TRIVERS, R. 1971. The Evolution of Reciprocal Altruism. Quarterly Review of Biology 46 (1): 35-57.

Disponível em https://greatergood.berkeley.edu/images/uploads/Trivers-EvolutionReciprocalAltruism.pdf.

Acessado em 25/05/2017

Recebido: $02 / 02 / 2021$

Aprovado: 12/03/2021

Publicado: 30/04/2021 
